\title{
Incidence and relative risk of peripheral neuropathy in cancer patients treated with eribulin: a meta-analysis
}

\author{
Ling Peng ${ }^{1}$, Yun Hong ${ }^{2}$, Xianghua $\mathrm{Ye}^{3}$, Peng Shi ${ }^{4,5}$, Junyan Zhang ${ }^{6}$, Yina Wang ${ }^{1}$ and \\ Qiong Zhao ${ }^{1}$ \\ ${ }^{1}$ Department of Thoracic Oncology, The First Affiliated Hospital, School of Medicine, Zhejiang University, Hangzhou, Zhejiang \\ Province, China \\ ${ }^{2}$ Department of Pharmacy, The First Affiliated Hospital, School of Medicine, Zhejiang University, Hangzhou, Zhejiang \\ Province, China \\ ${ }^{3}$ Department of Radiotherapy, The First Affiliated Hospital, School of Medicine, Zhejiang University, Hangzhou, Zhejiang \\ Province, China \\ ${ }^{4}$ Department of Medical Statistics, Children's Hospital of Fudan University, Shanghai, China \\ ${ }^{5}$ Center for Evidence-Based Medicine, Fudan University, Shanghai, China \\ ${ }^{6}$ Bothwin Clinical Study Consultant, Seattle, WA, USA
}

Correspondence to: Qiong Zhao, email: doczq.2008@hotmail.com

Keywords: eribulin, peripheral neuropathy, incidence, relative risk, meta-analysis

Received: July 10, 2017 Accepted: August 30, $2017 \quad$ Published: September 19, 2017

Copyright: Peng et al. This is an open-access article distributed under the terms of the Creative Commons Attribution License 3.0 (CC BY $3.0)$, which permits unrestricted use, distribution, and reproduction in any medium, provided the original author and source are credited.

\section{ABSTRACT}

Background: Eribulin is a microtubule inhibitor, which is approved for the treatment of breast cancer. Peripheral neuropathy has been reported in the studies of eribulin, but the incidence and relative risk (RR) of eribulin-associated peripheral neuropathy varied greatly in cancer patients. The purpose of this meta-analysis was to determine the overall incidence and RR of eribulin-associated peripheral neuropathy in cancer patients.

Materials and Methods: Pubmed database and Embase and abstracts presented at the American Society of Clinical Oncology (ASCO) meetings were systematically reviewed for primary studies. Eligible studies included prospective clinical trials and expanded access programs of cancer patients treated with eribulin. Statistical analyses were performed to calculate the incidences, RRs, and $95 \%$ confidence intervals (CIs).

Results: Altogether, 4,849 patients from 19 clinical trials were selected for this meta-analysis. The incidences of all-grade and high-grade peripheral neuropathy were $27.5 \%$ (95\% CI: $23.3-32.4 \%$ ) and $4.7 \%$ (95\% CI: $3.6-6.2 \%$ ), respectively. The relative risks of peripheral neuropathy of eribulin compared to control were increased for all-grade ( $R R=1.89,95 \%$ CI: 1.10-3.25) but not statistically significant for highgrade $(R R=2.98,95 \%$ CI: 0.71-12.42).

Conclusions: The use of eribulin is associated with an increased incidence of peripheral neuropathy. The RR is increased for all-grade peripheral neuropathy.

\section{INTRODUCTION}

Eribulin mesylate (E7389) is a synthetic analog of halichondrin $\mathrm{B}$, which is a nontaxane microtubule inhibitor, isolated from the rare marine sponge Halichondria okadai [1]. Eribulin was approved for the treatment of metastatic breast cancer patients who have received two chemotherapeutic regimens previously.
Although eribulin is well-tolerated, significant toxicities are reported with its use. Chemotherapyinduced peripheral neuropathy (CIPN) is one of the major toxicities, which will lead to a significant decrease in the patient's quality of life. Symptoms of CIPN are symmetric painful paresthesia, numbness, peripheral ataxia, and weakness [2]. Monitoring and management of peripheral neuropathy is of great importance because 
serious peripheral neuropathy may lead to poor quality of life and dose reduction.

Due to the limited sample size in each primary study, great variation exits concerning the reported incidences of peripheral neuropathy among studies. To determine the incidence and RR of peripheral neuropathy associated with eribulin, we aim to investigate the incidence and the RR of eribulin-associated peripheral neuropathy by performing a meta-analysis. We have also studied potential factors affecting the effect size, including tumor type and trial design.

\section{RESULTS}

\section{Study selection and characteristics}

Our search yielded 361 potentially relevant studies on eribulin from PubMed and Embase. Among them, 345 were excluded after preliminary review (Figure 1). Eighteen studies were included for the final analysis. The search for ASCO abstracts yielded 132 studies, among which only 1 abstract met inclusion criteria. Altogether, we included 19 clinical trials in the final analysis (Table 1). The studies were published between 2009 and 2017. The baseline information of the 19 primary studies were shown in Table 1, including 3 phase III randomized controlled trials, 14 phase II trials, one phase IV trial, and 1 EAP (expanded access program). The sample size of the primary studies ranged from 51 to 951 patients (median sample size, 108 patients).
All studies reported the incidence of peripheral neuropathy associated with eribulin. The underlying malignancies include breast cancer, lung cancer, prostate cancer, urothelial cancer and sarcoma. For calculation of the RRs, 4 clinical trials were pooled [3-6]. The meta-analysis adheres to the guidelines of the Preferred Reporting Items for Systematic review and Meta-Analyses (PRISMA) statement [7].

\section{Incidence of peripheral neuropathy}

The incidences of peripheral neuropathy of this meta-analysis were shown in Figure 2. Data for allgrade peripheral neuropathy included a total of 3,782 patients from 19 trials. Incidence of all-grade peripheral neuropathy ranged from $11.8 \%$ to $57.1 \%$ with the lowest incidence in a phase 2 trial by Inoue et al. [8], and the highest incidence in breast cancer patients [9]. The summary incidence of all-grade peripheral neuropathy was $27.5 \%$ (95\% CI: $23.3 \%-32.4 \%)$, according to the random-effects model (Heterogeneity test: $I^{2}=99.8 \%$, $P<0.0001$ ) (Figure 2A).

Eighteen trials reported the incidence of high-grade peripheral neuropathy, with incidence ranging from 0 to $19.64 \%$. The highest incidence was reported in a phase 2 trial in breast cancer patients [9], and the lowest incidence in sarcoma patients [10]. The summary incidence of highgrade peripheral neuropathy was $4.7 \%$ (95\% CI: $3.6 \%-$ $6.2 \%$ ), using a random effects model (Heterogeneity test: $\left.I^{2}=97.9 \%, P<0.0001\right)$ (Figure 2B).

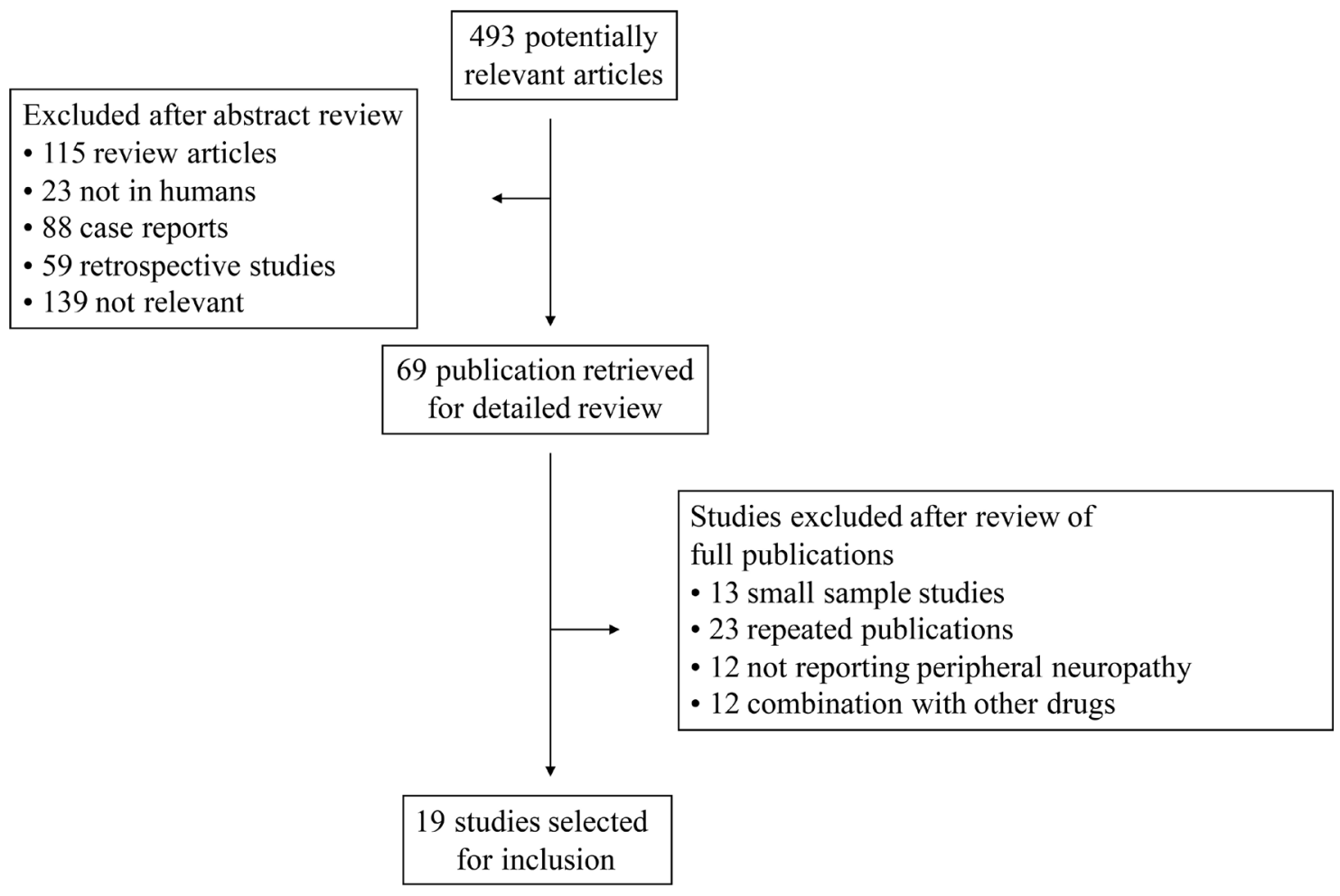

Figure 1: Selection process for the trials included in the meta-analysis. 
Table 1: Main characteristics and results of the eligible studies

\begin{tabular}{|c|c|c|c|c|c|c|c|c|c|c|c|c|}
\hline Year & Study & Phase & Source & Disease & Trial & Drug & Calculation & Dose & $\begin{array}{c}\text { All- } \\
\text { grade }\end{array}$ & High-grade & Patients & Clinical Trial No. \\
\hline 2017 & Watanabe [19] & 4 & Pubmed & Breast & Single-arm & Eribulin & Incidence & $1.4 \mathrm{mg} / \mathrm{m}^{2} \mathrm{~d} 1 \mathrm{~d} 8 \mathrm{Q} 3 \mathrm{w}$ & 160 & 26 & 951 & NCT01463891 \\
\hline 2017 & Park [20] & 4 & Pubmed & Breast & Single-arm & Eribulin & Incidence & $1.4 \mathrm{mg} / \mathrm{m}^{2} \mathrm{~d} 1 \mathrm{~d} 8 \mathrm{Q} 3 \mathrm{w}$ & 27 & 2 & 101 & NCT01961544 \\
\hline 2016 & Yardley [21] & 2 & Pubmed & Breast & Single-arm & Eribulin & Incidence & $1.4 \mathrm{mg} / \mathrm{m}^{2} \mathrm{~d} 1 \mathrm{~d} 8 \mathrm{Q} 3 \mathrm{w}$ & 16 & 3 & 65 & NCT01427933 \\
\hline 2017 & Kawai [22] & 2 & Pubmed & Sarcoma & Single-arm & Eribulin & Incidence & $1.4 \mathrm{mg} / \mathrm{m}^{2} \mathrm{~d} 1 \mathrm{~d} 8 \mathrm{Q} 3 \mathrm{w}$ & 16 & 0 & 51 & NCT01458249 \\
\hline \multirow[t]{2}{*}{2016} & Schöffski [3] & 3 & Pubmed & Sarcoma & RCT & Eribulin & $\begin{array}{c}\text { Incidence } \\
\text { \& RR }\end{array}$ & $1.4 \mathrm{mg} / \mathrm{m}^{2} \mathrm{~d} 1 \mathrm{~d} 8 \mathrm{Q} 3 \mathrm{w}$ & 46 & 4 & 226 & NCT01327885 \\
\hline & & & & & & Dacarbazine & & & 8 & 0 & 224 & - \\
\hline 2016 & Inoue [8] & 2 & Pubmed & Breast & Single-arm & Eribulin & Incidence & $1.4 \mathrm{mg} / \mathrm{m}^{2} \mathrm{~d} 1 \mathrm{~d} 8 \mathrm{Q} 3 \mathrm{w}$ & 6 & 1 & 51 & 000006965 \\
\hline 2016 & Aftimos [23] & EAP & Pubmed & Breast & Single-arm & Eribulin & Incidence & $1.4 \mathrm{mg} / \mathrm{m}^{2} \mathrm{~d} 1 \mathrm{~d} 8 \mathrm{Q} 3 \mathrm{w}$ & 65 & 10 & 154 & NCT01240421 \\
\hline 2015 & Quinn [24] & 2 & ASCO & Urothelial & Single-arm & Eribulin & Incidence & $1.4 \mathrm{mg} / \mathrm{m}^{2} \mathrm{~d} 1 \mathrm{~d} 8 \mathrm{Q} 3 \mathrm{w}$ & 67 & NR & 150 & NCT00365157 \\
\hline \multirow[t]{2}{*}{2015} & Kaufman [4] & 3 & Pubmed & Breast & $\mathrm{RCT}$ & Eribulin & $\begin{array}{l}\text { Incidence } \\
\text { \& RR }\end{array}$ & $1.4 \mathrm{mg} / \mathrm{m}^{2} \mathrm{~d} 1 \mathrm{~d} 8 \mathrm{Q} 3 \mathrm{w}$ & 149 & 38 & 544 & NCT00337103 \\
\hline & & & & & & Capecitabine & & & 75 & 5 & 546 & - \\
\hline 2014 & McIntyre [9] & 2 & Pubmed & Breast & Single-arm & Eribulin & Incidence & $1.4 \mathrm{mg} / \mathrm{m}^{2} \mathrm{~d} 1 \mathrm{~d} 8 \mathrm{Q} 3 \mathrm{w}$ & 32 & 11 & 56 & NCT01268150 \\
\hline \multirow[t]{2}{*}{2013} & Vahdat [5] & 2 & Pubmed & Breast & $\mathrm{RCT}$ & Eribulin & $\begin{array}{l}\text { Incidence } \\
\quad \& \mathrm{RR}\end{array}$ & $1.4 \mathrm{mg} / \mathrm{m}^{2} \mathrm{~d} 1 \mathrm{~d} 8 \mathrm{Q} 3 \mathrm{w}$ & 16 & 5 & 51 & NCT00879086 \\
\hline & & & & & & Ixabepilone & & & 22 & 10 & 50 & - \\
\hline 2012 & Spira [25] & 2 & Pubmed & Lung & Single-arm & Eribulin & Incidence & $\begin{array}{c}1.4 \mathrm{mg} / \mathrm{m}^{2} \mathrm{~d} 1 \mathrm{~d} 8 \mathrm{Q} 3 \mathrm{w} / \\
\mathrm{Q} 4 \mathrm{w}\end{array}$ & 21 & 2 & 103 & NA \\
\hline 2012 & Gitlitz [26] & 2 & Pubmed & Lung & Single-arm & Eribulin & Incidence & $1.4 \mathrm{mg} / \mathrm{m}^{2} \mathrm{~d} 1 \mathrm{~d} 8 \mathrm{Q} 3 \mathrm{w}$ & 20 & 2 & 66 & NCT00400829 \\
\hline 2012 & de Bono [27] & 2 & Pubmed & Prostate & Single-arm & Eribulin & Incidence & $1.4 \mathrm{mg} / \mathrm{m}^{2} \mathrm{~d} 1 \mathrm{~d} 8 \mathrm{Q} 3 \mathrm{w}$ & 15 & 3 & 108 & NCT00278993 \\
\hline 2012 & Aogi [28] & 2 & Pubmed & Breast & Single-arm & Eribulin & Incidence & $1.4 \mathrm{mg} / \mathrm{m}^{2} \mathrm{~d} 1 \mathrm{~d} 8 \mathrm{Q} 3 \mathrm{w}$ & 19 & 3 & 81 & NCT00633100 \\
\hline 2011 & Schöffski [29] & 2 & Pubmed & Sarcoma & Single-arm & Eribulin & Incidence & $1.4 \mathrm{mg} / \mathrm{m}^{2} \mathrm{~d} 1 \mathrm{~d} 8 \mathrm{Q} 3 \mathrm{w}$ & 43 & 4 & 127 & NCT00413192 \\
\hline \multirow[t]{2}{*}{2011} & Cortes [6] & 3 & Pubmed & Breast & $\mathrm{RCT}$ & Eribulin & $\begin{array}{l}\text { Incidence } \\
\text { \& RR }\end{array}$ & $1.4 \mathrm{mg} / \mathrm{m}^{2} \mathrm{~d} 1 \mathrm{~d} 8 \mathrm{Q} 3 \mathrm{w}$ & 174 & 41 & 503 & NCT00388726 \\
\hline & & & & & & $\mathrm{TPC}^{*}$ & & & 45 & 5 & 247 & - \\
\hline 2010 & Cortes [30] & 2 & Pubmed & Breast & Single-arm & Eribulin & Incidence & $1.4 \mathrm{mg} / \mathrm{m}^{2} \mathrm{~d} 1 \mathrm{~d} 8 \mathrm{Q} 3 \mathrm{w}$ & 95 & 17 & 291 & NA \\
\hline 2009 & Vahdat [31] & 2 & Pubmed & Breast & Single-arm & Eribulin & Incidence & $\begin{array}{c}1.4 \mathrm{mg} / \mathrm{m}^{2} \mathrm{~d} 1 \mathrm{~d} 8 \mathrm{Q} 3 \mathrm{w} / \\
\mathrm{Q} 4 \mathrm{w}\end{array}$ & 32 & 5 & 103 & NA \\
\hline
\end{tabular}

Summary table of studies included in the meta-analysis. Abbreviations: N, number of patients; CI, confidence interval; RCT, randomized controlled trial; NR, not reported.

The trials were subgrouped by the underlying malignancy (breast vs non-breast cancer patients), and the incidence was calculated. All-grade incidence for breast and non-breast cancer patients was $28.5 \%$ (95\% CI: $23.4 \%-34.7 \%)$ and $25.4 \%$ (95\% CI: $18.1 \%-$ $35.7 \%$ ), respectively. Breast cancer patients have a higher incidence of high-grade peripheral neuropathy than non-breast cancer patients $\left(5.8 \%, 95 \%\right.$ CI: $4.3 \%{ }_{-}$ $8.0 \%$ and $2.4 \%, 95 \%$ CI: $1.8 \%-3.2 \%$, breast vs nonbreast cancer patients, respectively). The incidence of all-grade and high-grade peripheral neuropathy in nonbreast cancer patients (lung cancer, prostate cancer, urothelial cancer and sarcoma) ranged from $13.89 \%$ to $44.67 \%$, and 0 to $3.15 \%$, respectively. However, due to the limited primary studies of each type of cancer involved, subgroup analysis of separate cancer type was not performed. The cancer type can partly explain the heterogeneity between the trials in terms of highgrade incidence, and the subgroup difference reached the level of statistical significance. We also calculated the differences in incidence according to study type (randomized controlled trial vs single-arm), and no significant differences were found (Figure 3). We conducted a random-effects meta-regression to quantify the effect of those factors, and the results indicated that the incidence of high-grade peripheral neuropathy varied with cancer type (breast vs non-breast cancer patients, $P=0.017)$, while all-grade incidence did not seem to be affected by cancer type $(P=0.568)$. Study type (randomized controlled trial vs single-arm study) and clinical trial phase did not affect all-grade and highgrade incidence (all $P>0.05$ ).

\section{Relative risk of peripheral neuropathy}

RR of peripheral neuropathy associated with eribulin compared with control was determined. The control arms included dacarbazine [3], capecitabine [4], ixabepilone [5], and TPC (treatment of physician's choice) [6]. The pooled RR showed that eribulin increased the risk of all-grade peripheral neuropathy in cancer patients with a RR of $1.89,95 \%$ CI: $1.10-3.25$, suggesting a nearly two-fold risk for developing peripheral neuropathy with eribulin compared with control (Figure 2C). Significant heterogeneity was found $\left(I^{2}=87.1 \% ; P<0.0001\right)$. The RR for high-grade peripheral neuropathy was not increased $\left(\mathrm{RR}=2.98,95 \%\right.$ CI: $0.71-12.42$, Figure 2D) $\left(I^{2}=83.1 \%\right.$, $P<0.0001)$. 


\section{Publication bias}

Eighteen studies reporting all-grade and high-grade peripheral neuropathy induced by eribulin resulted in an Egger's test score of $P=0.894$ and $P=0.072$, respectively (Figure 4). Results for publication bias from trials investigating RR were also shown in Figure $4(P=0.534$ and 0.789 for RR of all-grade and high-grade peripheral neuropathy, respectively).

\section{Sensitivity analysis}

Sensitivity analysis was performed to test the robustness and stability of our results. The significance estimate of pooled results was not influenced by omitting any single study (Figure 5).

\section{DISCUSSION}

Eribulin mesylate is an halichondrin B analog, which binds to tubulin and microtubules. Eribulin was approved for the treatment of metastatic breast cancer patients, which is administered as a single agent at $1.4 \mathrm{mg} / \mathrm{m}^{2}$ IV on days 1 and 8 of a Q3W (every 3 weeks) cycle. The mechanism of eribulin is a novel action, which is distinct from other tubulin-targeted drugs, such as taxanes, epothilones, and vinca alkaloids [11]. Peripheral neuropathy is one of the non-hematological toxicities of eribulin. The underlying mechanism of eribulin-associated peripheral neuropathy is not entirely understood. The data on the summary incidence RR of eribulin-associated peripheral neuropathy are rather limited. We conducted a meta-analysis to determine the incidence and RR of peripheral neuropathy in patients receiving eribulin.

This is the first meta-analysis evaluating the incidence and RR of peripheral neuropathy associated with eribulin. In this meta-analysis, prospective clinical trials and expanded access programs of eribulin were included. The main finding of the present study is that RRs of peripheral neuropathy of eribulin compared to control were increased for all-grade $(\mathrm{RR}=1.89,95 \% \mathrm{CI}$ : $1.10-3.25)$ but not for high-grade $(\mathrm{RR}=2.98,95 \% \mathrm{CI}$ :

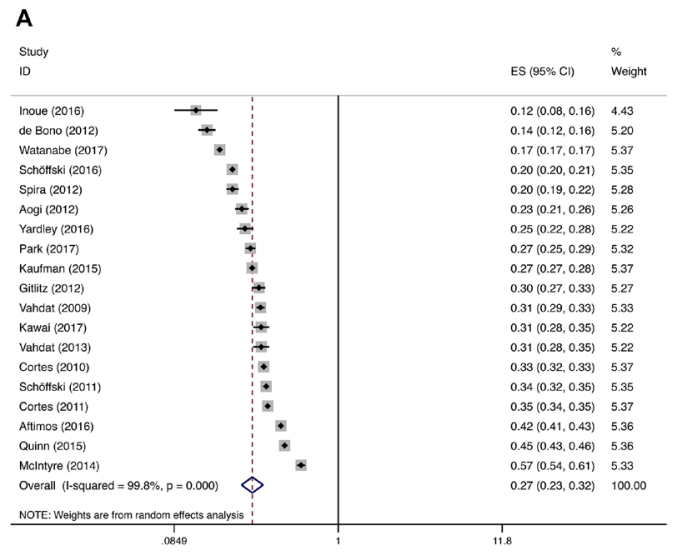

B
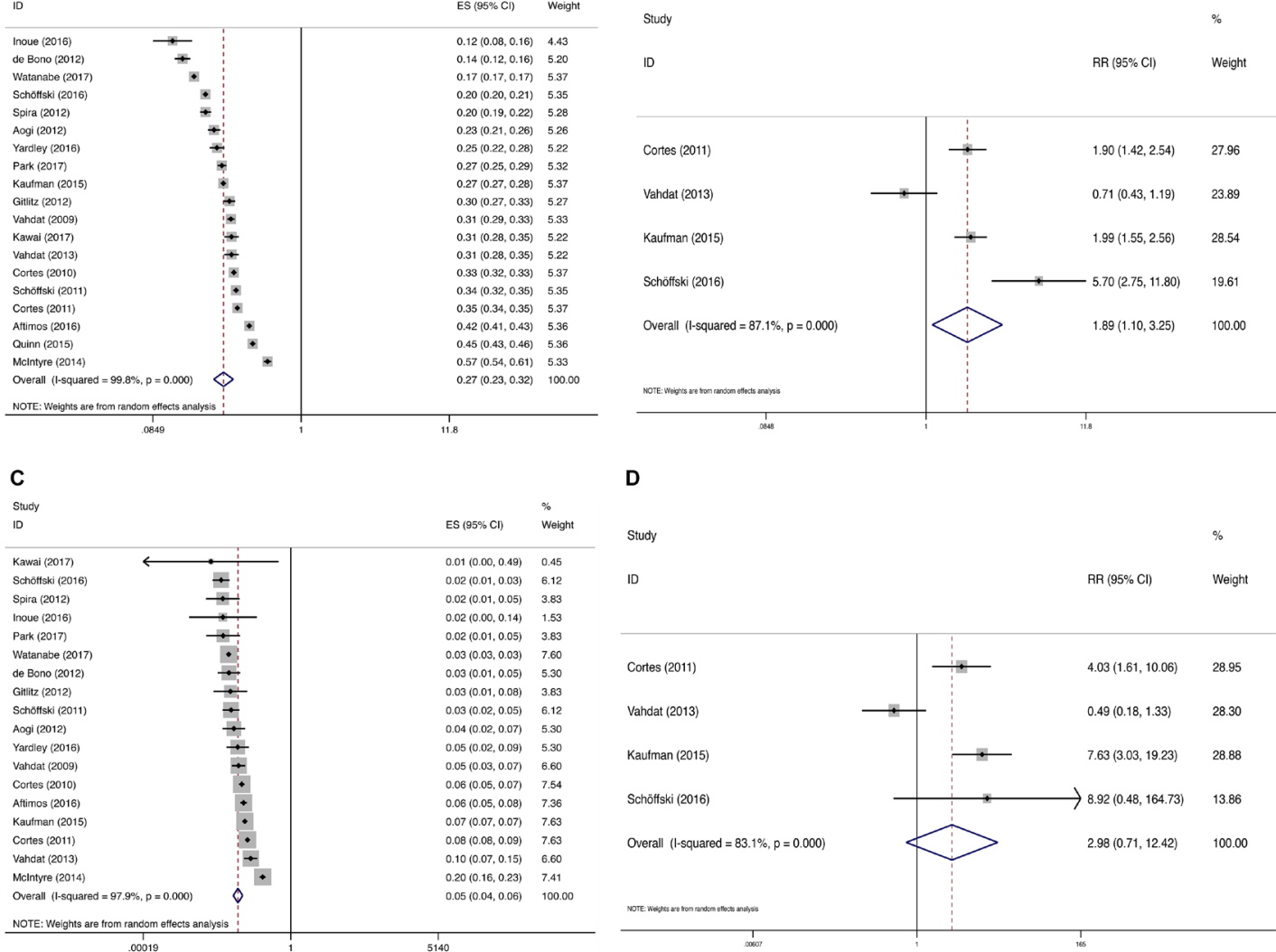

D

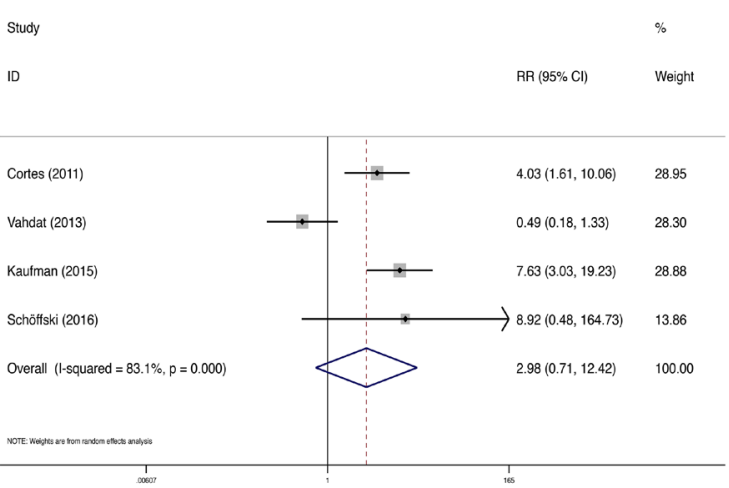

Figure 2: Forest plot for meta-analysis of relative risk and incidence of all-grade and high-grade peripheral neuropathy in cancer patients treated with eribulin. Each study was shown by the name of the lead author and year of publication. The summary incidence and RR were also shown in the figure. Relative risk of eribulin-associated all-grade and high-grade peripheral neuropathy versus control from controlled trials of patients with cancer. Plots are arranged as follows: (A) Incidence of all-grade peripheral neuropathy; (B) Incidence of high-grade peripheral neuropathy; (C) Relative risk of eribulin-associated all-grade peripheral neuropathy vs control; (D) Relative risk of eribulin-associated high-grade peripheral neuropathy vs control. 
0.71-12.42). Risk of high-grade peripheral neuropathy was not increased, for which we suggest there might be several possible reasons. In primary studies, if the events are rare (ie, $<5 \%$ ), they are often under-reported. Clinical trials are usually designed to investigate efficacy, but not specifically to address adverse events.

Our meta-analysis results demonstrated that eribulin is associated with an increased incidence of peripheral neuropathy. The overall incidence of allgrade and high-grade peripheral neuropathy was $28.6 \%$ (95\% CI: 24.2-33.8\%) and 4.7\% (95\% CI: 3.6-6.2\%, respectively. We performed a subgroup analysis based on different tumor types. Considering the small number of events, the subgroup analysis can only be explained with caution. Indeed, the incidence of eribulin-associated peripheral neuropathy in breast cancer patients, the most common tumor type in our meta-analysis, seems to have a trend to increase in all-grade peripheral neuropathy

\section{A}
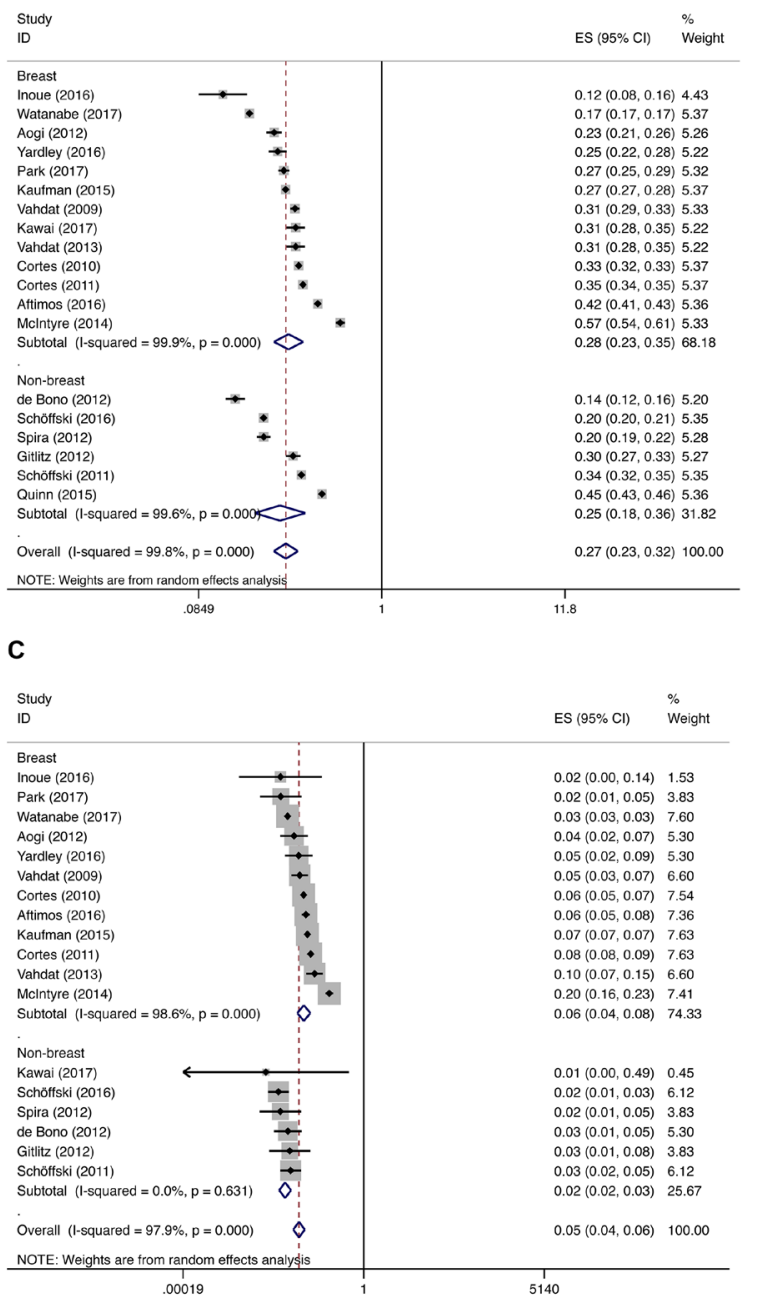

(30.3\% vs $25.4 \%$ for breast vs non-breast cancer patients, respectively), while statistically significant higher in highgrade peripheral neuropathy than non-breast cancers. The incidence and risk of peripheral neuropathy might be higher in the older and heavily treated population. Prior exposure to other neurotoxic agents complicates the risk for an individual patient. While breast cancer patients have a longer overall survival, patients receiving multiple lines of chemotherapy would have a higher chance of developing peripheral neuropathy. No significant difference was found between study design or trial phase of eribulin for all-grade and high-grade incidence of peripheral neuropathy. However, there is still the possibility of a real difference because of the limited number of trials and sample size of patient population included.

In addition to eribulin, other anti-neoplastic drugs, such as taxanes, bortezomib, cisplatin, also display
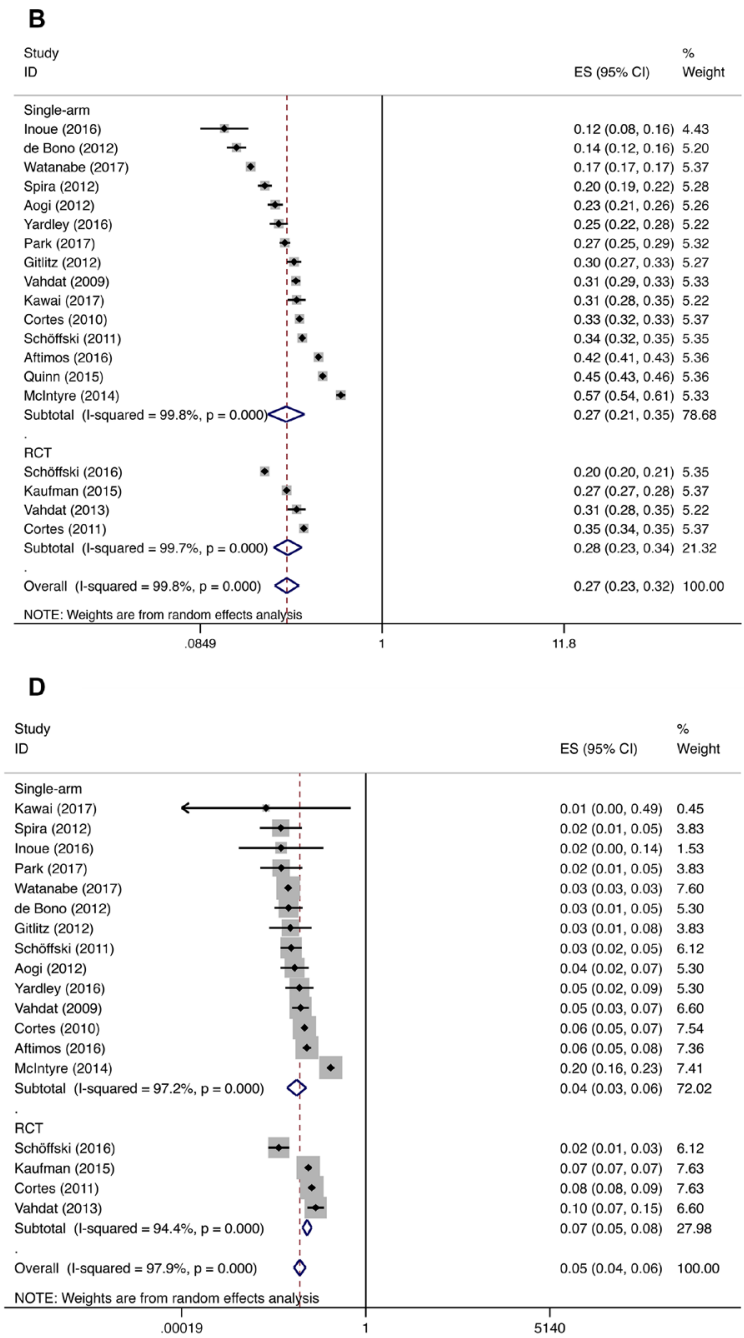

Figure 3: Subgroup analysis for incidence of all-grade and high-grade peripheral neuropathy. Each study was shown by the name of the lead author and year of publication. The summary incidences were also shown in the figure. Plots are arranged as follows: (A) Incidence of all-grade peripheral neuropathy in breast vs non-breast cancer patients; (B) Incidence of all-grade peripheral neuropathy in breast vs non-breast cancer patients; (C) Incidence of all-grade peripheral neuropathy in single-arm vs RCT; (D) Incidence of high-grade peripheral neuropathy in single-arm vs RCT. 

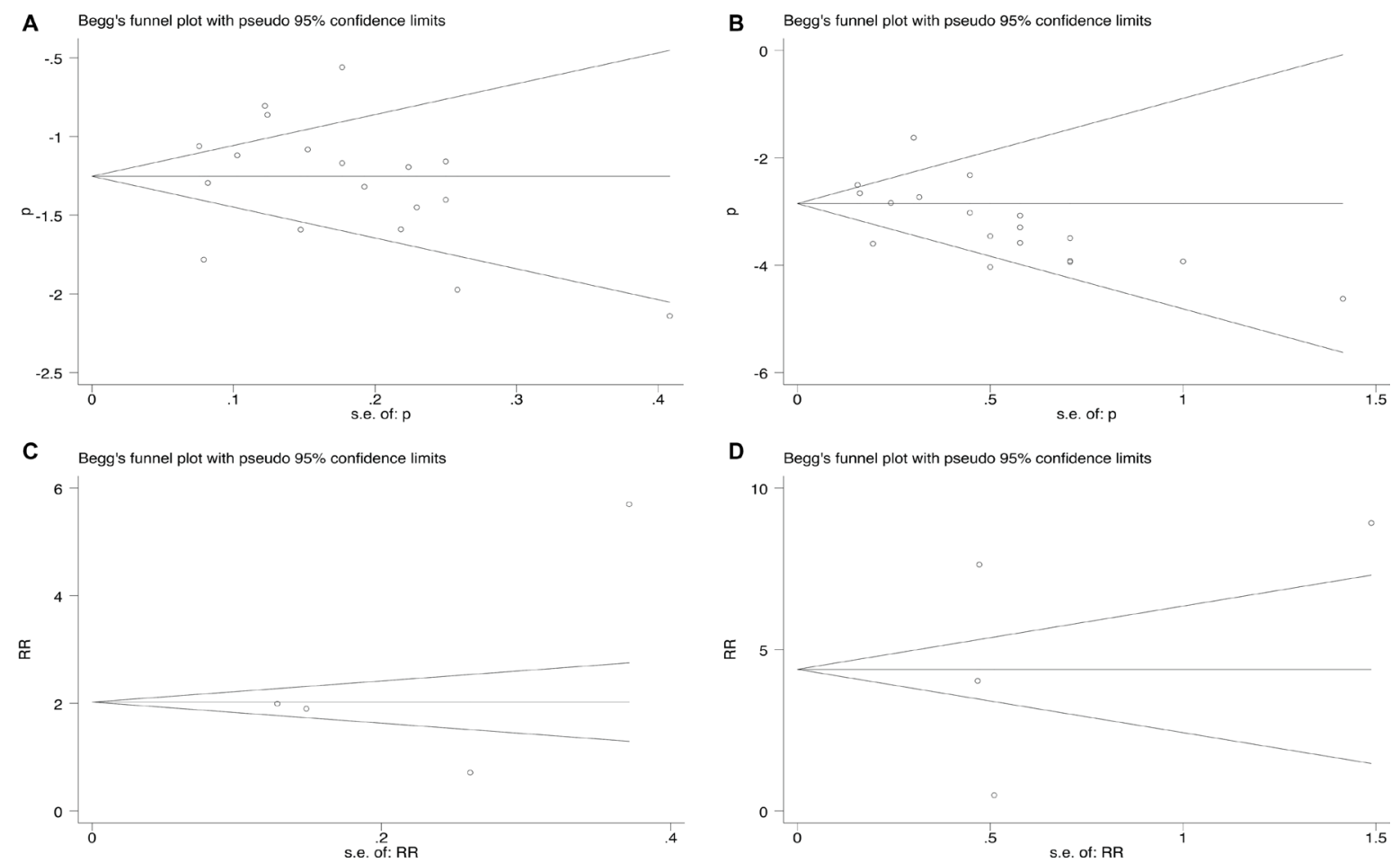

Figure 4: Funnel plot for studies included in the meta-analysis. Each study was shown by the name of the lead author and year of publication. The summary incidences were also shown in the figure. Plots are arranged as follows: (A) Publication bias of studies of incidence of all-grade peripheral neuropathy; (B) Publication bias of studies of incidence of high-grade peripheral neuropathy; (C) Publication bias of studies of RR of all-grade peripheral neuropathy; (D) Publication bias of studies of high-grade peripheral neuropathy.
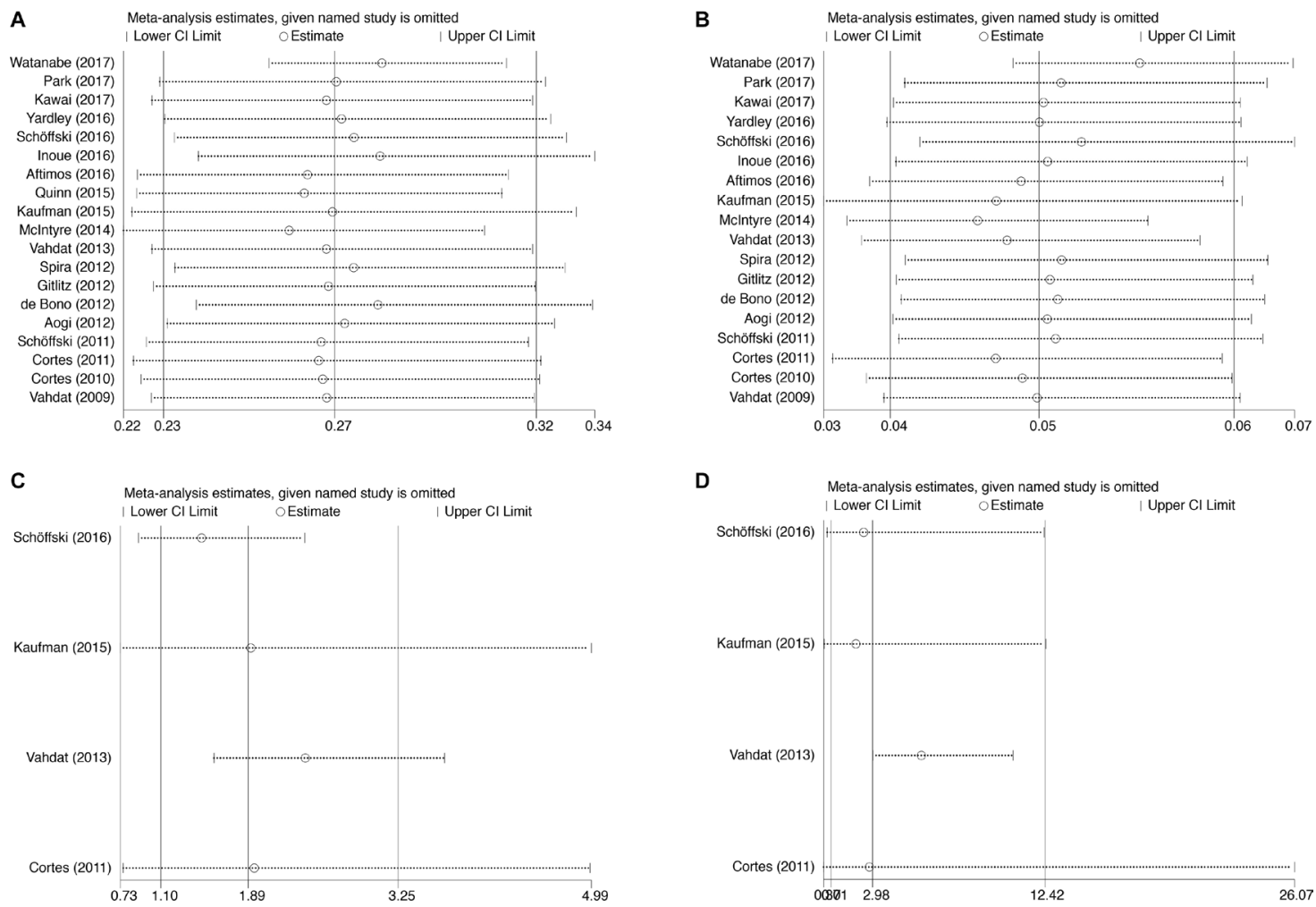

Figure 5: Sensitivity analysis for studies included in the meta-analysis. Plots are arranged as follows: (A) Sensitivity analysis of incidence of all-grade peripheral neuropathy; (B) Sensitivity analysis of incidence of high-grade peripheral neuropathy; (C) Sensitivity analysis of RR of all-grade peripheral neuropathy; (D) Sensitivity analysis of RR of high-grade peripheral neuropathy. 
dose-limiting toxicity of peripheral neuropathy $[12,13]$. Depending upon the severity of the peripheral neuropathy, the offending agent is usually reduced, delayed, or discontinued. The manufacturer's package insert also suggested to suspend the use of eribulin in patients who developed grade 3 or 4 peripheral neuropathy, until the resolution to grade 2 or less. Palliative care studies have been conducted to prevent or alleviate the symptom. Current management is mostly based on previous experiences and the severity of the symptom, which may be graded using the Common Terminology Criteria for Adverse Events (CTCAE) classification system. Few treatments are available for peripheral neuropathy. The ASCO guideline recommended treatment option for chemotherapy-induced peripheral neuropathy is duloxetine [14].

Our meta-analysis is not without limitations. One limitation of our meta-analysis is the lack of access to individual patient data, and these studies are conducted at various institutions with different baseline characteristics (Table 1). Secondly, a continuity correction of 0.5 subjects was applied, which might slightly overestimated the actual event rate. Thirdly, there were heterogeneity among primary clinical studies regarding tumor types and sample sizes.

Despite the above limitations, our meta-analysis is the first study to systematically quantify the incidence and RR of eribulin-associated peripheral neuropathy. The RRs of peripheral neuropathy of eribulin compared to control were increased for all-grade but not for highgrade. We observed a nearly two-fold RR of all-grade peripheral neuropathy with eribulin. High-grade peripheral neuropathy events were raised only slightly in the trend but not statistically, probably because of the limited sample size and events reported. Physicians should be aware of the possibility of increased peripheral neuropathy, especially in high-risk patients, and adverse events need careful monitoring, surveillance and reporting.

\section{MATERIALS AND METHODS}

\section{Search strategy and study selection}

An comprehensive search of PubMed database and Embase citations was conducted, with search terms "Eribulin", “E7389”; AND "cancer", “carcinoma", "sarcoma"; AND "clinical trial"; AND "sensory neuropathy", "peripheral neuropathy", "chemotherapy induced peripheral neuropathy", "CIPN". The search was limited to published studies in English. Abstracts from ASCO were also searched. The upper date limit of June 2017 was applied, with no lower date limit. The clinical trial registration website (http://www.clinicaltrials.gov) was also searched. The manufacturer's package insert of eribulin was also reviewed to obtain relevant information.

The inclusion criteria in this meta-analysis were: (1) prospective clinical trials conducted with cancer patients;
(2) patients assigned to receive eribulin; (3) events available for peripheral neuropathy. Only the complete publication was included when multiple publications of the same trial were identified. Trials with relatively small number of patients (less than 50) were excluded. Phase I studies were excluded due to the different drug doses in these trials. Abstracts were read by two independent readers (LP and XY). Articles that could not be determined based on title and abstract were full-text reviewed.

\section{Study selection}

Data extraction was performed by two authors (LP and XY) independently, and discrepancies were resolved by consensus. Peripheral neuropathy was reported in the toxicity profile of each study. Peripheral neuropathy were recorded according to versions 4.0 of the CTCAE of National Cancer Institute (http:/ctep.cancer.gov/reporting/ ctc_archive.html).

\section{Data analysis}

Detailed information was collected from the primary studies, including the following items: first author, publication year, underlying malignancy, sample size, dose of eribulin, and control arm. If data were not reported, items were treated as "NR (not reported)". The proportion of patients with peripheral neuropathy and $95 \%$ confidence interval (CI) were retrieved for each study. Studies which had a control arm were used to calculate RRs of peripheral neuropathy. For a study that reported zero event, we used the half-integer correction to calculate the RR and variance [15]. Authors of the primary studies were not contacted for additional data.

Heterogeneity was calculated employing the $\chi^{2}$-based $Q$ test and $I^{2}$ statistic [16]. Heterogeneity was considered statistically significant when $P$ heterogeneity $<0.1$ or $I^{2}>$ $50 \%$. Data were analyzed using a random effects model, if heterogeneity existed. Otherwise, a fixed effects model was used. An inverse variance statistical method was used to calculate the pooled incidence. We conducted a meta-regression analysis to test for variation in incidence estimates by other confounding factors. We performed subgroup analyses by different tumor type or trial design to explore the reasons for heterogeneity. $P<0.05$ was considered significant. Publication bias was evaluated by using the Begg's and Egger's tests [17, 18]. Sensitivity analysis was performed by sequential omission of a single individual study to assess the stability and reliability of results. All calculations were performed by STATA version 14.0 (Stata Corporation, College Station, TX).

\section{Author contributions}

All authors participated in the design of the study and contributed to the manuscript development. Data were 
collected and interpreted in collaboration with all authors. All the authors vouch for the accuracy and completeness of the data reported and the adherence of the study to the protocol, and all the authors made the decision to submit the manuscript for publication.

\section{ACKNOWLEDGMENTS} studies.

We are indebted to the authors of the primary

\section{CONFLICTS OF INTEREST}

The authors declare no conflicts of interest.

\section{FUNDING}

This study was supported by a grant from the Natural Science Foundation of China (Grant number: 81402179).

\section{REFERENCES}

1. Towle MJ, Salvato KA, Budrow J, Wels BF, Kuznetsov G, Aalfs KK, Welsh S, Zheng W, Seletsky BM, Palme MH, Habgood GJ, Singer LA, Dipietro LV, et al. In vitro and in vivo anticancer activities of synthetic macrocyclic ketone analogues of halichondrin B. Cancer Res. 2001; 61:1013-21.

2. Stubblefield MD, Burstein HJ, Burton AW, Custodio CM, Deng GE, Ho M, Junck L, Morris GS, Paice JA, Tummala S, Von Roenn JH. NCCN task force report: management of neuropathy in cancer. J Natl Compr Canc Netw. 2009; 7 Suppl 5: S1-S26.

3. Schoffski P, Chawla S, Maki RG, Italiano A, Gelderblom H, Choy E, Grignani G, Camargo V, Bauer S, Rha SY, Blay JY, Hohenberger P, D'Adamo D, et al. Eribulin versus dacarbazine in previously treated patients with advanced liposarcoma or leiomyosarcoma: a randomised, open-label, multicentre, phase 3 trial. Lancet. 2016; 387:1629-37. https://doi.org/10.1016/S0140-6736(15)01283-0.

4. Kaufman PA, Awada A, Twelves C, Yelle L, Perez EA, Velikova G, Olivo MS, He Y, Dutcus CE, Cortes J. Phase III open-label randomized study of eribulin mesylate versus capecitabine in patients with locally advanced or metastatic breast cancer previously treated with an anthracycline and a taxane. J Clin Oncol. 2015; 33:594-601. https://doi. org/10.1200/JCO.2013.52.4892.

5. Vahdat LT, Garcia AA, Vogel C, Pellegrino C, Lindquist DL, Iannotti N, Gopalakrishna P, Sparano JA. Eribulin mesylate versus ixabepilone in patients with metastatic breast cancer: a randomized Phase II study comparing the incidence of peripheral neuropathy. Breast Cancer Res Treat. 2013; 140:341-51. https://doi.org/10.1007/s10549$013-2574-2$
6. Cortes J, O'Shaughnessy J, Loesch D, Blum JL, Vahdat LT, Petrakova K, Chollet P, Manikas A, Dieras V, Delozier T, Vladimirov V, Cardoso F, Koh H, et al. Eribulin monotherapy versus treatment of physician's choice in patients with metastatic breast cancer (EMBRACE): a phase 3 open-label randomised study. Lancet. 2011; 377:914-23. https://doi.org/10.1016/S0140-6736(11)60070-6.

7. Moher D, Liberati A, Tetzlaff J, Altman DG. Preferred reporting items for systematic reviews and meta-analyses: the PRISMA statement. PLoS Med. 2009; 6:e1000097.

8. Inoue K, Saito T, Okubo K, Kimizuka K, Yamada H, Sakurai T, Ishizuna K, Hata S, Kai T, Kurosumi M. Phase II clinical study of eribulin monotherapy in Japanese patients with metastatic breast cancer who had well-defined taxane resistance. Breast Cancer Res Treat. 2016; 157:295-305. https://doi.org/10.1007/s10549-016-3808-x.

9. McIntyre K, O'Shaughnessy J, Schwartzberg L, Gluck S, Berrak E, Song JX, Cox D, Vahdat LT. Phase 2 study of eribulin mesylate as first-line therapy for locally recurrent or metastatic human epidermal growth factor receptor 2-negative breast cancer. Breast Cancer Res Treat. 2014; 146:321-8. https://doi.org/10.1007/s10549-014-2923-9.

10. Kawai A, Araki N, Naito Y, Ozaki T, Sugiura H, Yazawa Y, Morioka H, Matsumine A, Saito K, Asami S, Isu K. Phase 2 study of eribulin in patients with previously treated advanced or metastatic soft tissue sarcomadagger. Jpn J Clin Oncol. 2017; 47:137-44. https://doi.org/10.1093/jjco/ hyw 175.

11. Jordan MA, Kamath K, Manna T, Okouneva T, Miller HP, Davis C, Littlefield BA, Wilson L. The primary antimitotic mechanism of action of the synthetic halichondrin E7389 is suppression of microtubule growth. Mol Cancer Ther. 2005; 4:1086-95. https://doi.org/10.1158/1535-7163.MCT-040345 .

12. Peng L, Bu Z, Ye X, Zhou Y, Zhao Q. Incidence and risk of peripheral neuropathy with nab-paclitaxel in patients with cancer: a meta-analysis. Eur J Cancer Care (Engl). 2015. https://doi.org/10.1111/ecc.12407.

13. Peng L, Ye X, Zhou Y, Zhang J, Zhao Q. Meta-analysis of incidence and risk of peripheral neuropathy associated with intravenous bortezomib. Support Care Cancer. 2015; 23:2813-24. https://doi.org/10.1007/s00520-015-2648-2.

14. Hershman DL, Lacchetti C, Dworkin RH, Lavoie Smith EM, Bleeker J, Cavaletti G, Chauhan C, Gavin P, Lavino A, Lustberg MB, Paice J, Schneider B, Smith ML, et al. Prevention and management of chemotherapy-induced peripheral neuropathy in survivors of adult cancers: American Society of Clinical Oncology clinical practice guideline. J Clin Oncol. 2014; 32:1941-67. https://doi. org/10.1200/JCO.2013.54.0914.

15. Friedrich JO, Adhikari NK, Beyene J. Inclusion of zero total event trials in meta-analyses maintains analytic consistency and incorporates all available data. BMC Med Res Methodol. 2007; 7:5. https://doi.org/10.1186/14712288-7-5. 
16. Zintzaras E, Ioannidis JP. Heterogeneity testing in metaanalysis of genome searches. Genet Epidemiol. 2005; 28:123-37.

17. Yusuf S, Peto R, Lewis J, Collins R, Sleight P. Beta blockade during and after myocardial infarction: an overview of the randomized trials. Prog Cardiovasc Dis. 1985; 27:335-71.

18. Begg CB, Mazumdar M. Operating characteristics of a rank correlation test for publication bias. Biometrics. 1994; 50:1088-101.

19. Watanabe J, Ito Y, Ohsumi S, Mizutani M, Tashiro H, Sakurai K, Takahashi M, Saito T, Tsurutani J, Mukai H, Yoshinami T, Takao S, Yamamoto Y, et al. Safety and effectiveness of eribulin in Japanese patients with locally advanced or metastatic breast cancer: a post-marketing observational study. Invest New Drugs. 2017. https://doi. org/10.1007/s10637-017-0486-4.

20. Park YH, Kim TY, Im YH, Lee KS, Park IH, Sohn J, Lee $\mathrm{SH}$, Im SA, Kim JH, Kim SH, Lee SJ, Koh SJ, Lee KH, et al. Feasibility and Efficacy of Eribulin Mesilate in Korean Patients with Metastatic Breast Cancer: Korean Multicenter Phase IV Clinical Study Results. Cancer Res Treat. 2017; 49:423-9. https://doi.org/10.4143/crt.2016.191.

21. Yardley DA, Reeves J, Dees EC, Osborne C, Paul D, Ademuyiwa F, Soliman H, Guthrie T, Andersen J, Krekow L, Choksi J, Daniel B, Danso M, et al. Ramucirumab With Eribulin Versus Eribulin in Locally Recurrent or Metastatic Breast Cancer Previously Treated With Anthracycline and Taxane Therapy: A Multicenter, Randomized, Phase II Study. Clin Breast Cancer. 2016; 16:471-9.e1. https://doi. org/10.1016/j.clbc.2016.07.005.

22. Kawai A, Araki N, Naito Y, Ozaki T, Sugiura H, Yazawa Y, Morioka H, Matsumine A, Saito K, Asami S, Isu K. Phase 2 study of eribulin in patients with previously treated advanced or metastatic soft tissue sarcoma. Jpn J Clin Oncol. 2017; 47:137-44. https://doi.org/10.1093/jjco/ hyw175.

23. Aftimos P, Polastro L, Ameye L, Jungels C, Vakili J, Paesmans M, van den Eerenbeemt J, Buttice A, Gombos A, de Valeriola D, Gil T, Piccart-Gebhart M, Awada A. Results of the Belgian expanded access program of eribulin in the treatment of metastatic breast cancer closely mirror those of the pivotal phase III trial. Eur J Cancer. 2016; 60:117-24. https://doi.org/10.1016/j.ejca.2016.03.010.

24. Quinn DI, Ruel N, Twardowski PW, Groshen SG, Dorff TB, Pal SK, Stadler WM, Apario A, Lara PN, Newman EM. Eribulin in advanced urothelial cancer (AUC) patients (pts): A california cancer consortium trial (NCI/CTEP 7435). J Clin Oncol. 2015; 33.
25. Spira AI, Iannotti NO, Savin MA, Neubauer M, Gabrail NY, Yanagihara RH, Zang EA, Cole PE, Shuster D, Das A. A phase II study of eribulin mesylate (E7389) in patients with advanced, previously treated non-small-cell lung cancer. Clin Lung Cancer. 2012; 13:31-8. https://doi.org/10.1016/j. cllc.2011.06.010.

26. Gitlitz BJ, Tsao-Wei DD, Groshen S, Davies A, Koczywas M, Belani CP, Argiris A, Ramalingam S, Vokes EE, Edelman M, Hoffman P, Ballas MS, Liu SV, et al. A phase II study of halichondrin B analog eribulin mesylate (E7389) in patients with advanced non-small cell lung cancer previously treated with a taxane: a California cancer consortium trial. J Thorac Oncol. 2012; 7:574-8. https://doi. org/10.1097/JTO.0b013e31823f43ca.

27. de Bono JS, Molife LR, Sonpavde G, Maroto JP, Calvo E, Cartwright TH, Loesch DM, Feit K, Das A, Zang EA, Wanders J, Agoulnik S, Petrylak DP. Phase II study of eribulin mesylate (E7389) in patients with metastatic castration-resistant prostate cancer stratified by prior taxane therapy. Ann Oncol. 2012; 23:1241-9. https://doi. org/10.1093/annonc/mdr380.

28. Aogi K, Iwata H, Masuda N, Mukai H, Yoshida M, Rai Y, Taguchi K, Sasaki Y, Takashima S. A phase II study of eribulin in Japanese patients with heavily pretreated metastatic breast cancer. Ann Oncol. 2012; 23:1441-8. https://doi.org/10.1093/annonc/mdr444.

29. Schoffski P, Ray-Coquard IL, Cioffi A, Bui NB, Bauer S, Hartmann JT, Krarup-Hansen A, Grunwald V, Sciot R, Dumez H, Blay JY, Le Cesne A, Wanders J, et al. Activity of eribulin mesylate in patients with soft-tissue sarcoma: a phase 2 study in four independent histological subtypes. Lancet Oncol. 2011; 12:1045-52. https://doi.org/10.1016/ S1470-2045(11)70230-3.

30. Cortes J, Vahdat L, Blum JL, Twelves C, Campone M, Roche H, Bachelot T, Awada A, Paridaens R, Goncalves A, Shuster DE, Wanders J, Fang F, et al. Phase II study of the halichondrin B analog eribulin mesylate in patients with locally advanced or metastatic breast cancer previously treated with an anthracycline, a taxane, and capecitabine. J Clin Oncol. 2010; 28:3922-8. https://doi.org/10.1200/ JCO.2009.25.8467.

31. Vahdat LT, Pruitt B, Fabian CJ, Rivera RR, Smith DA, Tan-Chiu E, Wright J, Tan AR, Dacosta NA, Chuang E, Smith J, O'Shaughnessy J, Shuster DE, et al. Phase II study of eribulin mesylate, a halichondrin B analog, in patients with metastatic breast cancer previously treated with an anthracycline and a taxane. J Clin Oncol. 2009; 27:295461. https://doi.org/10.1200/JCO.2008.17.7618. 